\title{
El comercio sexual en Chile: ambiguedades y contradicciones discursivas
}

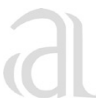 \\ Ma Cecilia Fernández Darraz \\ Recibido: 8 de noviembre de 2010 \\ Aprobado: 5 de febrero de 2011
}

\begin{abstract}
En este trabajo analizo, desde una perspectiva crítica, dos tipos de discursos en relación con el comercio sexual en Chile. Por una parte, el emitido por autoridades políticas y, por otra, el contenido en el texto de una Ordenanza Municipal de la comuna de Las Condes en la región Metropolitana (Chile) que busca regular el ejercicio de dicha actividad.

Empleando los modelos de Representación de Actores/as Sociales (van Leeuwen, 1996 y Fairclough, 2003), concluyo que los discursos analizados incluyen con especial prominencia a los/as ciudadanos/as y residentes del sector y excluyen a las mujeres y a los/as clientes que participan directamente de la actividad. Asimismo, se evidencia una postura ambigua donde coexisten la aceptación y el rechazo del comercio sexual, a la vez que las voces discursivas adhieren a la postura ideológica que sostiene que la prostitución es una actividad económica como cualquiera otra.
\end{abstract}

Palabras clave: Comercio sexual - análisis crítico del discurso - representación de actores/as sociales.

Estudiante doctorado Ciencias Humanas Mención Discurso y Cultura, Universidad Austral de Chile. Becaria CONICYT Estudios Doctorado en Chile, 2009. Correo electrónico: fernandezdarraz@gmail.com 


\title{
Commercial sexual exploitation in Chile: discursive ambiguities and contradictions
}

\begin{abstract}
I use this article to analyze two types of discourses from a critical point of view, in relation to the commercial sexual exploitation in Chile. First, I should speak about the discourse expressed by political authorities. Second, I should speak about the content of a Municipal Ordinance of Las Condes commune in Chile Metropolitan Area, intended to regulate exercise of such an activity.

By using Social Player Representation models (van Leeuwen, 1996 and Fairclough, 2003) I should conclude that analyzed discourses specifically include caregivers and residents of the sector and exclude women and customers who directly participate in the activity. Likewise, an ambiguous position where acceptance and rejection of commercial sexual exploitation coexist while discursive voices follow the ideological position which states that prostitution is an economic activity as any one else.
\end{abstract}

Key words: commercial sexual exploitation, critical analysis of discourse, representation of social actors/actresses. 


\section{Introducción}

El comercio sexual es un tema escasamente debatido en Chile y sobre el cual el Estado no se pronuncia con total claridad. Más allá de los avances legislativos y de la eficacia de las normas jurídicas vigentes, pareciera que hay acuerdo en que son condenables la prostitución infantil, el tráfico de personas y el proxenetismo. Respecto de la prostitución ejercida por mujeres mayores de 18 años, el discurso político es - al menos- ambiguo.

El debate internacional en torno al tema permite identificar dos posturas ideológicas que se traducen, con relativa nitidez, en los discursos públicos. Por un lado, la que ha intentado instalar el movimiento feminista, que plantea que la prostitución es un negocio dominado por la estructura patriarcal, que constituye una grave vulneración a los derechos humanos de las mujeres y que no puede, en modo alguno, ser considerado un trabajo como cualquiera otro. Por otro lado, la postura que sostiene que es un oficio tan antiguo como la humanidad misma y que, por lo tanto, se hace necesario regularlo en sus aspectos sanitarios, tributarios y de espacios de funcionamiento.

En Chile, durante el año 2006, se generó un debate en relación con la prostitución a partir de la situación particular de la comuna de Las Condes en la región Metropolitana. El alcalde, Francisco de La Maza, anunció la realización de un plebiscito con el propósito de que la ciudadanía decidiera sobre una medida que, a su juicio, contribuiría a erradicar el comercio sexual de la vía pública. La medida consistía en cerrar, durante las noches, el acceso a algunas calles del exclusivo barrio El Golf y permitir el ingreso sólo a sus residentes. En un plebiscito realizado en el mes de agosto de 2006, en el que participó cerca de un $50 \%$ de los/as ciudadanos/as, la mayor parte estuvo de acuerdo con la propuesta del alcalde. No obstante, la medida no pudo concretarse: la Contraloría General de la República la consideró inadmisible y, más tarde, la Corte Suprema ratificó un fallo de la Corte de Apelaciones que la calificaba de arbitraria e inconstitucional, en tanto las calles constituyen bienes nacionales de uso público. En reemplazo de esta iniciativa, en el mes de julio del año 2007, se dictó una ordenanza municipal que "regula y fija las normas básicas sobre la ocupación del espacio público, por actividades relacionadas con el comercio callejero, en los sectores residenciales de la comuna de Las Condes, y establece las infracciones que pueden ser cometidas por las personas intervinientes en dicho comercio" (artículo No 1 Ordenanza Local sobre Comercio Sexual en Lugares Públicos de la Comuna de Las Condes).

En este trabajo se analizan dos discursos. Por una parte, aquellos que fueron difundidos por los medios de comunicación electrónicos con ocasión del plebiscito y que fueron generados por autoridades políticas que se pronunciaron a favor o en contra del cierre de calles. Por otra parte, el texto de la Ordenanza Municipal sobre Comercio Sexual de la Comuna de Las Condes, en su apartado "vistos y téngase presente", que contiene los fundamentos de dicho instrumento.

Empleando la perspectiva del análisis crítico del discurso (ACD), particularmente el modelo de representación de actores/as sociales desarrollado por Theo van Leeuwen (1996) y Norman Fairclough (2003), intento responder las siguientes preguntas: ¿Cómo se representa en el discurso a los/as distintos actores/as sociales involucrados en el comercio sexual, en relación con su inclusión o exclusión, con la asignación de roles y con sus formas de nominación? ¿Existe una postura clara en el discurso de las autoridades políticas, respecto de la aceptación o rechazo del ejercicio de la prostitución? ¿La postura ideológica que predomina en el discurso político es la que condena la prostitución por considerarla una forma de abuso y discriminación hacia las mujeres, o aquella que la acepta como una actividad económica igual que otras?

\section{Marco teórico}

\subsection{El concepto de mercancía: objetos frente a personas}

Las mercancías constituyen un fenómeno cultural de carácter universal, y su intercambio, un rasgo 
esencial de la vida en sociedad (Kopytoff, 1991). Para el autor, mercancías son todos aquellos artículos que tienen un valor de uso y un valor de cambio, por lo tanto, circulan en el mercado y son intercambiadas por otra cosa de valor equivalente que, por lo general, es dinero. Por otro lado, el consumo se ha definido como un aspecto inherente al sistema social, en tanto los bienes juegan un rol importante en la conformación y mantenimiento de relaciones sociales (Douglas e Isherwood, 1990).

Las mercancías no tienen sólo un valor material, sino que también poseen un carácter cultural y cognoscitivo. Esto significa que la calificación de los objetos como mercancía varía de una cultura a otra, de una época a otra e incluso de una persona a otra en un mismo tiempo y contexto cultural (Kopytoff, 1991). Desde esta perspectiva, los bienes aseguran la subsistencia humana pero, más allá de eso, ponen en evidencia las categorías de una cultura (Douglas e Isherwood, 1990).

Para Douglas e Isherwood, las mercancías y los actos de consumo portan significados sociales, los cuales radican en las relaciones más que en el objeto en sí mismo. Si bien la mercantilización es un fenómeno universal, las expresiones del intercambio son culturales e idiosincráticas. Un aspecto importante tiene que ver con las restricciones que en los órdenes social, grupal o individual se establecen respecto de aquello que es susceptible de mercantilizar y lo que no lo es, y que en ocasiones entran en conflicto. Tales definiciones ponen en evidencia la "economía moral de una sociedad" (kopytoff, 1991).

Respecto de las restricciones socio-culturales de lo que se puede transar en el mercado, en la mayoría de las culturas de las que existe información, hay ciertas cosas que no se pueden mercantilizar. Es, precisamente, en el espacio de los servicios personales, aun libremente ofrecidos y recibidos, donde se pone en práctica un juicio moral respecto del valor de las personas y las cosas (Douglas e Isherwood, 1990). En este mismo plano, Kopytoff (1991) establece una clara distinción entre dos polos opuestos: los objetos físicos, que constituyen "el universo natural de las mercancías", y las personas, que representan el "universo de la individualización y la singularización". No obstante, reconoce que tanto la esclavitud como la mercantilización de personas libres, en algunas épocas y sociedades, constituyen expresiones que rompen con este ordenamiento. La mercantilización, entonces, no está circunscrita al mundo de los objetos.

\subsection{Las mujeres: una histórica mercancía}

La concepción de las mujeres como objetos de intercambio está socialmente normalizada y situada, para muchos/as, en el plano de lo natural. Esta visión tiene su origen en la condición y posición de opresión en que las mujeres han estado históricamente y en todas las sociedades de las que se tiene información. Para algunas, la génesis de la opresión de las mujeres está en la instalación del patriarcado, definido como una estructura familiar y social que institucionaliza, sobre ellas y los/as niños/as, el dominio masculino y la expansión de dicho dominio sobre las mujeres en la sociedad en general (Lerner, 1986).

Rubin (1986) opta por un concepto alternativo. Define el "sistema sexo/género" como el "conjunto de disposiciones por el que una sociedad transforma la sexualidad biológica en productos de la actividad humana". Su opción conceptual se fundamenta en el hecho de que no en todas las culturas la opresión de las mujeres se sostiene en una estructura social que asigna el poder a la paternidad.

Patriarcado o sistema sexo-género, lo cierto es que los orígenes de la condición subordinada de las mujeres se asocian a una construcción cultural y no a hechos naturales. Los estudios de género se han encargado de establecer la distinción entre lo natural y lo cultural, sosteniendo que aun cuando existen diferencias biológicas y anatómicas entre hombres y mujeres, éstas no explican la superioridad de un sexo sobre otro, La estratificación de género, por lo tanto, responde a una construcción cultural de la diferencia sexual (Lamas, 1986).

Para Bourdieu (2000) la instalación y mantenimiento de la visión social dominante de la diferencia sexual se sustenta en la coherencia entre 
las estructuras objetivas y las estructuras cognitivas. Con ello se naturaliza un estado de cosas que mantiene a los hombres en una situación de superioridad, la cual se vuelve incuestionable e imperceptible para la cognición humana. La dominación masculina es una institución "inscrita" en la objetividad de las estructuras sociales y en la subjetividad de las estructuras mentales.

Es en la obra de Levi-Strauss, donde Gayle Rubin encuentra buena parte de las explicaciones a la condición subordinada de las mujeres. En Las Estructuras elementales del parentesco, calificada por la autora como una "teoría de la opresión sexual" (Rubin, 1986) estaría la clave para comprender el problema. "La prohibición del uso sexual de la hija o de la hermana obliga a dar en matrimonio la hija o la hermana a otro hombre, y, al mismo tiempo, crea un derecho sobre la hija o la hermana de ese otro hombre" (Levi-Strauss, 1969; 51). En estas relaciones de intercambio las mujeres pasan a constituirse en el objeto regalado sobre el cual sólo tienen derechos los hombres: hombres son quienes obsequian y hombres quienes reciben.

El acto de intercambio que se realiza en el matrimonio tiene su base en la prohibición del incesto que, para Levi-Strauss, es un hecho social de carácter universal. No está aceptado usar sexualmente a una hija o una hermana, éstas deben entregarse en matrimonio a otro hombre. El tabú del incesto, entonces, es una regla que obliga a dar a otros a la madre, hermana o hija, más que una regla que prohíba casarse con alguna de ellas (Levi-Strauss, 1969, 481.) Para Rubin (1986), los sistemas de parentesco no sólo intercambian mujeres, sino también acceso sexual, relaciones genealógicas, nombres de linaje, entre otras.

El intercambio puede adoptar distintas formas dependiendo de la cultura. Mientras en algunas aparece de manera expresa, en otras puede estar implícito. (Rubin, 1986). No obstante, lejos de ser una práctica propia de sociedades tradicionales está presente, en distintas manifestaciones, también en sociedades complejas.

El estado histórico de opresión de las mujeres permite entender, e incluso legitimar, el comercio sexual de las mujeres. Tal como Marx afirma que una máquina puede transformarse en capital en una relación determinada, el estatus de esposa, mercancía o prostituta que adquiere una mujer se construye, también, en relaciones sociales determinadas (Rubin, 1986).

\subsection{La prostitución: sus orígenes y el estado de la discusión}

Mucho se ha hablado de que la prostitución es el oficio más antiguo de la humanidad. Lagarde (1990) advierte sobre visiones etnocéntricas que pueden llevar a confundirla con rituales mágicoreligiosos arcaicos. Para la autora, la génesis de la prostitución debe buscarse en la ruptura de la sociedad, en la división de los grupos, en la especialización genérica del trabajo y de los roles, y en la apropiación e intercambio de otros/as (Lagarde, 1990).

Para Lagarde (1990) la prostitución no es una profesión o un trabajo más, sino un modo de vida total. La define como "el espacio social, cultural y político de la sexualidad prohibida, explícita y centralmente erótica, de la sexualidad no fundante de futuro". La representación ideológica que circunscribe a las mujeres sólo a prostitutas, eróticas y malas mujeres se debe, en parte, a que en la prostitución se sintetizan y se niegan sus otras dimensiones: las de madres, esposas, profesionales, entre otras (Lagarde, 1990).

En Chile, así como en otros países del mundo, la prostitución no constituye un delito. Con independencia de los avances legislativos, hay acuerdo en relación a penalizar la prostitución infantil, el tráfico de personas o "trata de blancas" y el proxenetismo. Respecto de la prostitución ejercida por mujeres mayores de edad, el debate intenta concluir si puede o no considerarse una actividad económica como cualquiera otra y, por lo tanto, protegerse y regularse. Sobre este punto, en la discusión internacional existen dos visiones: la voluntarista sostiene que las mujeres tienen la libertad de elegir y que así como en el mercado se transan otros bienes y servicios personales, la mercantilización del cuerpo representa una opción legítima e individual. En este enfoque se promueven los deberes y los derechos 
de las mujeres, en tanto trabajadoras. La segunda visión es la determinista, que plantea que el ejercicio de la prostitución constituye la única salida a determinantes estructurales de carácter económico, sociocultural, psicológico y sexual y que en su mantenimiento hay responsabilidad de toda la sociedad. En este enfoque se denuncian la visión de las mujeres como objeto y mercancía, la situación de abuso permanente en que viven y la vulneración de sus derechos humanos fundamentales (Canales, 2005).

Movimientos como el Colectivo para la Defensa de los derechos de las prostitutas de Madrid sostienen que la prostitución es una institución patriarcal cuya principal función simbólica es mantener el control de la sexualidad de las mujeres y su situación de subordinación (Canales, 2005). En esta misma línea, Lagarde (1990) afirma que el mantenimiento de la prostitución resulta funcional a la reproducción de la poligamia masculina, de la virginidad, de la castidad, de la fidelidad y monogamia de las madres-esposas y a la perpetuación del matrimonio.

Pese a que la prostitución se sostiene en la participación de varios actores, clientes e intermediarios son casi invisibles en esta relación. El estigma social recae principalmente sobre la prostituta: proscrita sospechosa para la justicia, agente transmisor de enfermedades para el sistema de salud, foco de perversión para la moral dominante (Canales, 2005).

La posición que adopten los gobiernos frente a la prostitución va a depender del enfoque al cual adhieran y que representa la ideología de los grupos hegemónicos. Es así como se pueden adoptar modelos jurídicos abolicionistas, como es el caso de Suecia, donde se asume que mientras exista este tipo de prácticas no se podrá superar la situación de desigualdad y discriminación en que viven las mujeres. Este régimen concibe a la mujer como una víctima del sistema y condena al cliente y a terceros que se benefician de la explotación sexual de las mujeres. Otra posibilidad es la instauración de un modelo prohibicionista (Estados Unidos) que la declara ilegal y sanciona tanto a quienes venden como a quienes compran servicios sexuales. Una tercera posibilidad es el modelo reglamentista (Países Bajos) que entiende el ejercicio de la prostitución como parte de la realidad social y como una actividad pro fesional más, que requiere regulación (Canales, 2005).

La falta de legislación y de políticas públicas en la materia impide la adscripción del Estado chileno a uno de estos modelos. El Código Penal no sanciona la prostitución consentida de mayores de 18 años y donde no medie la trata de personas. Por otra parte, el Código Sanitario prohíbe la agrupación de trabajadoras sexuales en prostíbulos cerrados e impone controles de salud periódicos para evitar la propagación de enfermedades de transmisión sexual

\section{Marco analítico}

El discurso, entendido como una práctica social, es un medio para la reproducción de las ideologías, las cuales se definen como representaciones compartidas por una comunidad y que tienen funciones sociales específicas. Pueden estar orientadas a legitimar el poder y la desigualdad, o a "habilitar" a los grupos dominados para la lucha y la resistencia (van Dijk, 1999).

El análisis crítico del discurso (ACD) es una perspectiva que se ocupa de estudiar el rol del lenguaje en la producción y reproducción del abuso de poder en las relaciones sociales (van Dijk, 2001). Este enfoque estudia la desigualdad expresada y legitimada a través del discurso, sea éste conversacional, texto escrito, imágenes u otras formas semióticas (Wodak, 2001).

La representación de actores/as sociales en el discurso, en tanto conjunto de personas que de manera individual o colectiva se ubican estratégicamente en un sistema de poder (Pardo, 2005), permite identificar relaciones de dominación y resistencia entre distintos grupos, así como también analizar la transmisión y mantenimiento de la hegemonía ideológica (Fernández, 2010). En la representación de los actores/as sociales se ponen de manifiesto, entre otras, las posiciones de clase, género y etnia de los actores discursivos, que son los/as participantes activos de la interacción y quienes construyen imágenes 
de sí mismos, de los otros y de la realidad (Pardo, 2005).

Para su estudio, van Leeuwen (1996) propuso un "inventario socio-semántico", que con base en el análisis de categorías sociológicas y de sus realizaciones lingüísticas, permite desvelar relaciones sociales dominantes. Para efectos de este trabajo se emplearán las siguientes categorías: exclusión de actores sociales, que puede ser parcial o radical; los roles, activos o pasivos, que se les asignan a los/as actores/as en el discurso y las categorías de determinación e indeterminación, referida a la especificación de la identidad de los actores sociales o su representación como grupos o individuos anónimos.

Norman Fairclough (2003) complementa el modelo de van Leeuwen aportando elementos para el análisis de los eventos sociales. Plantea que los eventos sociales portan significados representacionales del mundo social y están constituidos por las actividades, las personas (con sus creencias, valores, historia, etc.), las relaciones sociales, los objetos, los medios, el tiempo, el lugar, el lenguaje y otras formas semióticas. En su propuesta, los actores son parte de un evento social y, recogiendo algunas de las dimensiones antes planteadas por van Leeuwen, releva las categorías de exclusión, inclusión y prominencia; los niveles de abstracción o concreción, y la organización y legitimación de los eventos.

Ambos autores afirman que la representación de actores en el discurso, en cuanto a sus niveles de exclusión, agencia, nominación, abstracción u otros, tiene directa relación con los propósitos de los/as productores textuales. Desde la perspectiva del ACD estos modelos permiten desvelar los significados políticos que subyacen a las opciones adoptadas en cada discurso.

\section{Análisis y discusión}

\subsection{Los discursos públicos}

Con ocasión del plebiscito realizado en la comuna de Las Condes - Chile - en el año 2006, se difundió a través de los medios de comunicación, un conjunto de discursos que expresaban posturas opuestas al cierre de calles. Por un lado, el alcalde De La Maza impulsor y acérrimo defensor de la medida y, por otro, el Intendente de la Región Metropolitana, Víctor Barrueto, manifestando rechazo en representación del Gobierno. Para este trabajo se analizaron los textos difundidos a través de los medios electrónicos emol.com, radio. uchile.cl, terra.cl y redprovida.com.'

Las distintas opciones de nominación de actores/as que se emplean en los discursos son las formas que los/as productores/as textuales utilizan para incluir actores o bien, los mecanismos para excluirlos parcial o radicalmente.

Ej. 1) "De la Maza reconoció además que el cierre de las calles puede implicar el traslado de las prostitutas y travestis a otro barrio, pero negó que eso le reste peso a la medida, pues lo principal, a su juicio, 'es que estas personas desparezcan del barrio, a través de cualquier mecanismo de control' (emol. com, 21 de agosto 2006).

En el primer ejemplo, las mujeres que ejercen el comercio sexual están incluidas en el discurso y son representadas por el alcalde como actoras generalizadas e indeterminadas, bajo la nominación "estas personas". Llama la atención la fuerza discursiva del enunciado que da cuenta del objetivo que se ha planteado la autoridad y que es "que estas personas desaparezcan del barrio". Para la autoridad, el propósito justifica "cualquier mecanismo de control", incluso la implementación de una medida cuya inconstitucionalidad fue advertida desde el momento de su primer anuncio.

El cierre de calles le permitiría al alcalde controlar un problema que causa molestia en su comuna y en un barrio en particular. Su objetivo es erradicarlo, sin importar que dicho "problema" se traslade a otro sector de la capital.

Ej. 2) "No obstante, aclaró que lo importante ahora es encontrar una solución definitiva y que 'el Gobierno y el intendente dejen de hacerse los ciegos - los sordos respecto de algo que es una realidad milenaria'. Según dijo, es absolutamente necesario definir un área dentro del plano metropolitano de

Los sitios elegidos fueron los que se encontraron disponibles en internet a la hora de realizar este trabajo. 
Santiago en que se pueda ejercer el comercio sexual" (emol.com, 21 de agosto 2006).

En este ejemplo el alcalde interpela al Gobierno y al intendente como actores que se encuentran pasivos frente a un problema que califica de "realidad milenaria". Bajo esta forma de nominar la prostitución se oculta una suerte de justificación y aceptación de la misma. Aún cuando no señala a quiénes, hay un llamado a definir un punto "en el plano" donde se pueda ejercer libremente el comercio sexual. En este enunciado se expresa una postura ambigua: el alcalde acepta el comercio sexual, pero no en el Golf, pues ahí se vuelve una molestia para sus habitantes.

Ej. 3) "Nadie está por encima de la ley, ni siquiera el alcalde De la Maza en su comuna (Las Condes). Hay que garantizar el libre tránsito de las personas, y nadie puede coartar la libertad de las personas", añadió Barrueto. (Diario electrónico Radio U. de Chile. 1 de septiembre de 2006).

En la forma impersonal "hay que garantizar", el Intendente de la Región Metropolitana está recordando que son las autoridades quienes deben asegurar "el libre tránsito". Barrueto hace alusión a la libertad de "las personas", representadas como actores generalizados. No queda claro, en este texto, si se refiere a los/as residentes que verían afectada su libertad de desplazamiento; a la ciudadanía en general, a quienes se les limitaría el acceso a ciertos sectores de la comuna; o a las mujeres que ejercen el comercio sexual en las calles. Este puede ser un mecanismo de exclusión de las prostitutas, en tanto no aparecen representadas como actoras y queda a interpretación del lector/a incluirlas o no en la nominación "las personas".

Ej 4) "También precisó que, de aplicarse esta medida, 'no solucionaría nada, ya que sólo correría el problema a unas cuadras de distancia', trasladando el conflicto a otras comunas aledañas, por lo que calificó la propuesta de De la Maza como una "mala idea'" (Diario electrónico Radio U. de Chile. 1 de septiembre de 2006).

En el ejemplo cuatro el representante del gobierno, al igual que el alcalde, no habla de las mujeres que ejercen el comercio sexual. Las suprime o excluye radicalmente del discurso bajo la nominalización "el problema", que se trasladará a otros sectores de la capital.

Ej. $\left.\mathrm{N}^{\circ} 5\right)$ "Finalmente, comentó que junto con alcaldes $y$ distintos representantes dio inicio a una mesa de trabajo para 'ver la mejor forma de regular esta actividad', sin descartar la implementación de un Barrio Rojo en Santiago" (Diario electrónico Radio U. de Chile. 1 de septiembre de 2006).

Como se observa en la mayoría de los ejemplos analizados, un mecanismo recurrente de exclusión de actores/as en el discurso es la nominalización. En estos casos, las mujeres no aparecen representadas como actoras sociales, siempre están ocultas bajo nominalizaciones como: "realidad milenaria", "el problema", "esta actividad". Además de ser una estrategia de supresión, estas formas de representación ocultan procesos o acciones y transforman a los/as actores/as en cosas.

Ej. No 6) "Yo invito al alcalde (Francisco) De la Maza a buscar formas que permitan si no eliminar completamente, por lo menos reducir el comercio sexual en esos sectores por vías que sean menos costosas desde el punto de vista de la libertad personal, desde el punto de vista de la libertad de transitar por sus propios barrios a la gente que vive alli", expresó el intendente. (Terra.cl. 20 de agosto de 2006)

En este caso, el Intendente precisa que la libertad personal que debe garantizarse es la de los residentes del barrio en cuestión. La autoridad vuelve a suprimir del discurso a las mujeres a través de la nominalización "el comercio sexual".

Ej. No 7) "el edil señaló que le sorprende que el Gobierno quiera impedir que los municipios, en forma autónoma, tomen medidas de regulación que van en beneficio de zonas residenciales" (Emol.com, 21 de agosto de 2006).

En este párrafo se identifican dos actores: el gobierno, como actor que a juicio del alcalde "quiere impedir" la acción y los municipios como actor que se representa afectado por la intromisión del gobierno. Las "zonas residenciales" es una nominalización que oculta a un tercer actor que serían los/as habitantes del sector. Estos últimos se representan como agentes pasivos en la medida que serían los beneficiarios de las me- 
didas adoptadas por la autoridad comunal, así como también son los afectados por la presencia del comercio sexual en las calles.

Ej. No 8: "Aclaró que en este tema entiende que hay derechos de ejercer la prostitución, pero 'mi asunto no es valórico, sino de defensa de los derechos de los ciudadanos que tienen familias en zonas residenciales'" (redprovida.com. 30 de abril de 2007).

Ej. No 9) "De la Maza aclaró que no está en un afán de perseguir a quienes ejercen "una profesión milenaria", sino proteger el bien común, especialmente de menores y familias de zonas residenciales afectados por la prostitución". (redprovida. com. 30 de abril de 2007)

En el ejemplo No 8 está señalada la actividad "ejercer la prostitución", que, además, el alcalde la define como un derecho. Sin embargo, se excluye a las personas o actoras sociales que tienen ese derecho con la forma impersonal "hay derechos".

En el ejemplo No 9 las mujeres que ejercen la prostitución están parcialmente excluidas del discurso bajo la representación "a quienes ejercen una profesión milenaria".

En los dos ejemplos, los actores incluidos con mayor prominencia en el discurso del alcalde son los/as ciudadanos/as, las familias de zonas residenciales y los/as niños/as. Todos ellos son representados como actores/as pasivos/as afectados/as por el comercio sexual y, por lo tanto, son el objetivo primordial de la medida que se pretende adoptar.

\subsection{La ordenanza municipal}

La ordenanza que regula el comercio sexual en la vía pública en la comuna de Las Condes consta de siete puntos en su apartado "vistos y téngase presente". Los tres primeros referidos a la salud de las personas, el cuarto a las mujeres que ejercen la prostitución, y los tres últimos centrados en la protección de la ciudadanía, de los/as niños/ as y de los bienes de uso público.

1.- "Que el ejercicio en la vía pública del comercio sexual, expone a las personas intervinientes a contraer o transmitir enfermedades de transmisión sexual;
2.- Que la Municipalidad debe velar y coadyuvar por la salud de las personas, promoviendo el libre e igualitario acceso a las acciones de promoción, protección y recuperación de la salud.

3.- Que la atención que prestan los Servicios de Salud para combatir las enfermedades de transmisión sexual es gratuita, comprendiéndose en ella el diagnóstico de la enfermedad, su tratamiento y control, conforme lo dispuesto en el Art. $8^{\circ}$ del D.S. N³62 de 1983 del Ministerio de Salud"

En estos tres puntos en que se aborda el aspecto de salud, las mujeres sólo están representadas en el primero, bajo la nominación "personas intervinientes". Se incluyen en el discurso como referencia a que constituyen un riesgo en la propagación de enfermedades de transmisión sexual. En este caso, se representan en un rol activo y pasivo a la vez, en tanto transmiten y contraen enfermedades. Los clientes no están expresamente representados, no obstante se infiere su inclusión dentro de la nominación "personas intervinientes".

En el segundo "vistos", el actor representado con mayor prominencia es la municipalidad, a quien se le asigna un rol activo que debe garantizar la salud de "las personas". Estas últimas aparecen como actoras indeterminadas, generalizadas, que puede ocultar a las mujeres que ejercen el comercio sexual, a los clientes, pero también a la ciudadanía en su conjunto.

En el tercer punto se excluye a todos /as los actores/as y el foco está puesto en "las enfermedades de transmisión sexual" y no en las perso nas que las padecen.

4.- "Que las personas que ejercen el comercio sexual callejero, están expuestas a situaciones de riesgo y violencia y al consumo de drogas y alcohol".

Este punto es el único que incluye y nomina a los/as actores/as con algún nivel de determinación: "personas que ejercen el comercio sexual". Las mujeres están representadas en un rol pasivo "expuestas a situaciones de riesgo". La prostitución, en este ejemplo, se relaciona con violencia explícita, consumo de drogas y alcohol, pero no hay consideraciones respecto de la violencia implícita en que se sostiene el comercio sexual y 
que se basa en una concepción objetual de las mujeres.

5.- "Que la necesidad de colaborar en la protección de los menores de edad, evitando la prostitución infantil y su participación en el comercio sexual, constituye un ineludible deber municipal.

6.- Que es deber del Municipio, la preservación y mantenimiento del espacio público como un lugar de sana convivencia, en el que cualquier persona pueda circular libremente, con pleno respeto a su dignidad $y$ derechos.

7.- Que las conductas de comercio sexual en los bienes nacionales de uso público ofenden el pudor y las buenas costumbres $y$ constituyen un deterioro en la calidad de vida de los vecinos de Las Condes, exponiendo a los menores de edad a la exhibición de actitudes de oferta y demanda de dicho comercio".

En el punto cinco, son los/as "menores de edad" los actores que están representados con mayor prominencia, en un rol pasivo como beneficiarios/as de la acción del municipio que aparece parcialmente excluido bajo la nominalización "deber municipal".

El visto $N^{\circ} 6$ incluye a las autoridades municipales nominalizadas en "el Municipio". "Cualquier persona" representa de manera indeterminada a la ciudadanía a la que debe garantizarse el derecho de circular libremente. Se suprime a las mujeres que ejercen la prostitución y a los clientes.

En el ejemplo No 7 las mujeres están parcialmente excluidas, ocultas en la nominalización "las conductas de comercio sexual". Sin embargo se les asigna un rol activo en tanto ofenden el pudor, las buenas costumbres y la calidad de vida de los/as residentes. Los vecinos de Las Condes y los/as niños/as se representan incluidos y con la mayor prominencia dentro del discurso, a la vez que son actores pasivos, afectados por el comercio sexual.

\section{Conclusiones}

En el comercio sexual en general, se pueden identificar tres actores involucrados de manera directa: las mujeres que ejercen la prostitución, los clientes que la promueven y, en muchos casos, un intermediario/a. Sin embargo, tanto en los discursos difundidos por los medios de comunicación como en la ordenanza municipal analizada, los intermediarios están radicalmente excluidos. Los clientes sólo se mencionan en un punto de la ordenanza, en el cual se representan parcialmente excluidos o en un segundo plano, dentro de la categoría "personas intervinientes". En el caso de las mujeres, se observa una tendencia a la exclusión parcial o radical.

Las opciones discursivas adoptadas por las autoridades les permiten hacer referencia a las mujeres pero no hablar expresamente de ellas. La mayoría de las veces están ocultas bajo nominalizaciones tales como: "comercio sexual", "esta actividad", "actividad milenaria". Aún estando excluidas radical o parcialmente, se representan en un rol activo, como una amenaza, una molestia y como personas que afectan las "buenas costumbres" y la calidad de vida de los vecinos, por lo cual es indispensable erradicarlas.

Los actores incluidos, con mayor prominencia en el discurso son los/as residentes del barrio, nominados como los/as ciudadanos/as, los vecinos y los niños. Están habitualmente representados como actores pasivos afectados y vulnerados en sus derechos.

Aún representando posturas políticas distintas, las autoridades tienen un discurso ambiguo respecto de la prostitución, donde coexisten la aceptación y el rechazo. Expresan cierto "respeto" por los derechos de las mujeres que ejercen el comercio sexual, pero declaran la necesidad de identificar "un punto en el plano" de la capital donde la actividad se pueda ejercer libremente.

Los discursos analizados adhieren a la postura ideológica que sostiene que la prostitución, aun siendo una molestia y una amenaza para "la ciudadanía", es una actividad económica como cualquiera otra y que, por lo tanto, debe regularse. Es un discurso que avala la mercantilización de personas, particularmente de mujeres, en tanto no se observan consideraciones en relación con la violencia simbólica que subyace al comercio sexual y a la dominación masculina en que se sustenta su ejercicio. 


\section{Referencias bibliográficas}

Bourdieu, P. (2000). La dominación masculina. Barcelona: Anagrama.

Canales Nettle, P. (2005). La regulación de la prostitución en la legislación comparada. Serie de Estudios No 325. Santiago: Biblioteca del Congreso Nacional.

Douglas, M y B. Isherwood. (1990). El mundo de los bienes. Hacia una antropología del consumo. México: Grijalbo.

Fernández, M. (2010). Las mujeres en el discurso pedagógico de la historia. Exclusiones, silencios y olvidos. Revista Universum, Universidad de Talca $N^{\circ}$ 25. Pp. $84-99$

Fairclough, N. (2003). Representations of social events. En: Analysing Discourse. Textual analisis for social research. Nueva York: Routledge, pp $134-155$

Kopytoff, I. (1991). La biografía cultural de las cosas: La mercantilización como proceso. En: Arjun Appadurai (Ed). La vida social de las cosas. México: Grijalbo.

Lagarde, M. (1990). Cautiverios de mujeres: madreesposas, monjas, putas, presas y locas. México: Universidad Nacional Autónoma de México.

Lamas, M. (1986). La antropología feminista y la categoría género. En: Nueva Antropología. Revista de Ciencias Sociales, ISSN 0185 - 0636, № 30, pp. $173-198$.

Lerner, G. (1990). La creación del patriarcado. Crítica: Barcelona.

Levi-Strauss, C. (1969). Las estructuras elementales del parentesco. Barcelona: Paidós.
Pardo, N. (2005). Representación de los actores armados en conflicto en la prensa Colombiana. En Revista Electrónica Forma y Función. Universidad Nacional de Colombia, enero - diciembre. № 18. Bogotá pp. 167 - 196

Rubin, G. (1986). El tráfico de mujeres: Notas sobre la "economía política del sexo. En: Revista Nueva Antropología. Universidad Nacional Autónoma de México. Año/vol. VIII, número 030, pp. 95 - 145

Van Dijk, T. (1999). Ideología. Una Aproximación interdisciplinaria. Barcelona: Gedisa.

Van Dijk, T. (2001). La multidisciplinariedad del análisis crítico del discurso: un alegato a favor de la diversidad. En: Wodak, R. y M. Meyer (comp.). Métodos de análisis crítico del discurso. Barcelona: Gedisa.

Van Leeuwen, T. (1996). The representation of social actors. En Carmen Rosa Caldas-Coulthard y Malcolm Coulthard (Eds.). Texts and Practices. Readings in Critical Discourse Análisis. Nueva York:Routledge, (pp $32-70$ )

Wodak, Ruth. (2001). El enfoque histórico del discurso. En: Wodak, R. y M. Meyer (comp.). Métodos de Análisis Crítico del Discurso. Barcelona: Gedisa.

Textos analizados

Ordenanza Local sobre Comercio sexual en lugares públicos de la comuna de Las Condes

www.emol.com. 21 de agosto de 2006

www.radio.uchile.cl. 1 de septiembre de 2006

www.redprovida.com. 30 de abril de 2007

www.terra.cl. 20 de agosto de 2006 